\title{
¡Bienvenido 2022! ¡La transición ha sido concretada!
}

\author{
A. Carolina Medina Díaz, (1) Karla Mayra Rezende, (1) Francisco Hernandez.
}

La Revista de Odontopediatría Latinoamericana ha pasado a adoptar la tendencia de las publicaciones científicas $\mathrm{y}$, a partir de este momento, es de flujo continuo. Es así como todas las ediciones del año en curso permanecerán abiertas (In progress). El logro de este sueño solo ha sido posible con la ayuda de todos los colegas, colaboradores, autores y revisores quienes, sin escatimar esfuerzos, trabajaron para concretarlo en la edición de 2022. Por lo tanto, esta edición estará compuesta por todos los trabajos aprobados y editados hasta el final del semestre, cuando el equipo editorial también publicará su archivo y editorial, procediendo al cierre de la edición.

Por supuesto, nos hubiera gustado celebrar este anuncio juntos en el XX Congreso Latinoamericano de Odontopediatría, el cual de llevó a cabo de manera híbrida en Guatemala en octubre de 2021, debido a las constantes incertidumbres en torno a la pandemia de COVID-19. Esperamos poderlo celebrar todos unidos en el XXI Congreso Latinoamericano de Odontopediatría en Monterrey, México, en noviembre de 2022.

De hecho, desde el 2020, con el decreto de la pandemia por el COVID-19, hemos tenido un número récord de envíos de artículos, videos y material didáctico para actualizar a la práctica clínica y a los padres respecto al cuidado bucal de sus hijos. Esto nos ha permitido ir impulsando rápidamente el proceso de comunicación y poniendo a disposición la investigación con numerosas ventajas para los lectores y contribuyendo así a su disponibilidad para lecturas y citas.

Este impacto del cambio a flujo continuo se evidenció en el aumento del número de envíos, mayor adhesión a la dinámica de la ciencia abierta, estímulo a publicar, por ahora, bilingüe y ser una revista de acceso abierto.

Nuestro equipo editorial cree que la medida favorecerá la experiencia de nuestros lectores, autores y toda la estimada comunidad que sigue la revista. También está destinado a cumplir con los requisitos para la indexación en grandes bases de datos. En consecuencia, esto nos ayudará a subir nuestra calificación frente a Qualis. De esta forma, mantenemos nuestro compromiso de difundir investigaciones con la mejor evidencia científica de forma globalizada y dinámica, como es nuestro mundo.

Finalmente, la revista ALOP es una de las revistas más importantes en el área de Odontopediatría latinoamericana, despertando el interés de investigadores de diferentes países latinoamericanos y ahora, con esta posibilidad, podemos estar seguros de que será una fuente privilegiada para la investigación y posgrados en educación y en la enseñanza de la Odontopediatría, cuyo producto final será conocimiento e información para la triada: investigadores/ clínicos y pacientes. 